\title{
Control of nanostructures generated in epoxy matrices blended with PMMA-b-PnBA-b-PMMA triblock copolymers
}

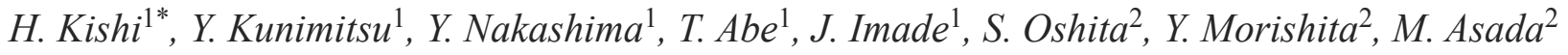 \\ ${ }^{1}$ Graduate School of Engineering, University of Hyogo, 2167, Shosha, Himeji, 671-2201 Hyogo, Japan \\ ${ }^{2}$ Kuraray Co. Ltd., 1-1-3, Otemachi, Chiyoda-ku, 100-8115 Tokyo, Japan
}

Received 22 May 2014; accepted in revised form 30 July 2014

\begin{abstract}
Stability of nanostructures of epoxy/acrylic triblock copolymer blends was studied. PMMA- $b$-PnBA- $b$-PMMA triblock copolymers (acrylic BCPs) having several compositions on the ratio of the block chains and the molecular weight were initially prepared and were blended with diglycidyl ether of bisphenol-A epoxy thermosets. The blends were cured using phenol novolac with tri phenyl phosphine (TPP) as the catalyst. Several nanostructures, such as spheres, cylinders, curved lamellae, were observed in the cured blends. The nanostructures were controlled by the molecular weight of the immiscible PnBA-block chain and the ratio of the PnBA in the blends. Moreover, the effect of the gel time to the nanostructures was examined by altering the trace amount of the TPP in the blends. The types of the nanostructures were almost kept irrespective of the gel time of the blends when the composition of the blends was maintained. This suggested the stability of the nanostructures of the epoxy/acrylic BCP blends made via the self-assembly mechanism, therefore a phase diagram of the cured blends was proposed.
\end{abstract}

Keywords: polymer blends and alloys, thermosets, nanomaterials, epoxy, block copolymer

\section{Introduction}

Epoxy thermosets are some of polymers widely used as structural materials and adhesives in many industries, such as the aerospace, automotive and electronics industries, for their reliable mechanical properties, high heat and solvent resistance. The distinguishing properties originate from the crosslinked chemical structure. However, the crosslinked structure tends to give low fracture toughness due to the restricted molecular motion of the polymer chains. Considerable effort to toughen the epoxy thermosets has been made in the past decades.

Relatively low crosslinked epoxy thermosets can be toughened by the incorporation of elastomer phases, but more highly crosslinked epoxy thermosets were difficult to toughen by the method [1-6]. Therefore, highly crosslinked epoxy polymer blends modified with engineering thermoplastic polymers have been researched [7-11]. The improvement in toughness depended on the phase morphology of the epoxy polymer blends. The phase separation occurs during the reaction process from the initial homogeneous mixture of the epoxy/thermoplastic blends [12, 13]. The driving force of the 'reaction-induced phase separation' is the elevated free energy of the mixture by the increase in the molecular weight via the reaction of epoxies and curing agents [12-14]. The phase sizes of the 'reaction-induced phase separation' were often from sub-micrometers to tens of micrometers.

In the background, block copolymers (BCPs) have attracted attention as toughening modifiers for nanostructured epoxy blends in the past years [15-37]. It is well known that the BCPs consisting of chemically distinct block chains form nano-phase structures in self-assembly [38-40]. Hillmyer et al. [15]

\footnotetext{
${ }^{*}$ Corresponding author, e-mail: kishi@eng.u-hyogo.ac.jp

(C) BME-PT
} 
and Lipic et al. [16] first reported nanostructured epoxy blends with the amphiphilic BCPs. Poly (ethylene oxide)- $b$-poly (ethyl ethylene) (PEO-PEE) diblock copolymer and poly (ethylene oxide)- $b$ poly (ethylene-alt-propylene) (PEO-PEP) diblock copolymer $[15,16]$ were synthesized as modifiers for diglycidyl ether of bisphenol-A (DGEBA) type epoxy thermosets. Hexagonally-packed cylindrical core-shell nanostructures were formed in the epoxy matrix blended with the $25 \mathrm{wt} \%$ PEO-PEE diblock copolymer [15]. In addition, the nanostructure of the uncured blends (DGEBA/PEO-PEP) was investigated using small-angle X-ray scattering (SAXS). By increasing the BCP amounts, the body-centered cubic packed spheres were changed to hexagonally packed cylinders, gyroid, and lamellar structures [16]. In-situ SAXS was also examined for an epoxy/ $69 \mathrm{wt} \%$ PEO-PEP diblock copolymer blend using an aromatic amine hardener. The phase structure changed from a gyroid to a lamella structure during the cure process [16]. Moreover, the same group synthesized many kinds of BCPs having PEO block for the epoxy polymer blends. The blends gave several nanostructures, such as spherical micelles, worm-like micelles, and vesicles [17-22].

Ritzenthaler and coworkers [23, 24] studied epoxy/ ABC triblock copolymer blends. 'Raspberry-like' (spheres-on-spheres) nanostructures were observed in the polystyrene- $b$-polybutadiene- $b$-poly (methyl methacrylate) triblock polymer (PS-PB-PMMA)/ DGEBA blends cured with MCDEA (4,4'-methylene-bis-(3-chloro 2,6-diethyl-aniline). The triblock copolymer having the increased PB segment showed 'onion-like' multilayered morphology in the DGEBA cured with MCDEA.

Nanostructured epoxy blends with polystyrene- $b$ polybutadiene (PS-PB) diblock copolymers were prepared by Serrano et al. [29]. The MCDEA-cured DGEBA/PS-PB diblock copolymer blends showed worm-like micelles and hexagonally-packed cylindrical micelles. The phase morphologies depended on the amount of the BCPs and the degree of epoxidation in the polybutadiene block.

In our previous study [30], poly (methyl methacrylate)- $b$-poly(n-butyl acrylate)- $b$-poly(methyl methacrylate) (PMMA- $b$-PnBA- $b$-PMMA) triblock copolymers (acrylic BCPs) were synthesized via living anionic polymerization. The acrylic BCPs were blended with the epoxy using a wide range of curing agents. Though aromatic amine (diamino diphenyl sulphone), acid anhydride (methyl nadic anhydride) and anionic polymerization catalyst (tris-dimethyl amino methyl phenol) gave macro-phase separation in the cured epoxy blends, phenol novolac (PN)cured epoxy/acrylic BCP blends gave nanostructures. Cylindrical micelles (both randomly-dispersed and regularly-arrayed) and spherical micelles were observed in the blends. The miscibility between the PMMA segments of the BCPs and the cured epoxy was a key factor to make the nanostructures in the blends. The fracture toughness of the epoxy/acrylic $\mathrm{BCP}$ blends having the nano-cylindrical structures was $2530 \mathrm{~J} / \mathrm{m}^{2}$. The toughness was twenty-fold compared to the unmodified epoxy thermoset.

In the literatures by Bates and coworkers $[15,16$, $18,20-22]$, nanostructures were generated via 'selfassembly' mechanism of epoxy/BCP blends. In other words, the nanostructures were pre-formed before the curing reaction of the blends, and were fixed by the network formation after the curing. On the other hand, Zheng and coworkers [31-34] showed that the nanostructures of the epoxy/BCP blends can be also generated via the 'reaction-induced phase separation'. In this case, it is not required that BCPs generate the nanostructures in self-assembly prior to the curing reaction; all the BCPs may be miscible with the thermoset precursors [34]. The formation of the nanostructures is due to the phase separation of the thermoset-phobic blocks of the BCPs from the matrix blends in the curing process [34]. Recently, Romeo et al. [37] reported that the cure cycle determined the types of the nanostructures of a DGEBA/PS- $b$-PMMA BCP blend, in which the nanostructures were generated via 'reactioninduced phase separation'. The difference of the mechanisms of the phase formation would have big effect on the stability of the nanostructures. Although various nanostructures were reported using many types of the epoxy/BCP blends, to the best of our knowledge, there are only limited literatures on the stability of the nanostructures in relation to the curing reaction rate. This is very important issue to be discussed in both scientific and industrial viewpoints.

The objective of the present study is twofold: (i) to find the key parameters to determine the nanostructures of the cured epoxy/acrylic BCP blends. The block composition and the molecular weight of the PMMA- $b$-PnBA- $b$-PMMA triblock copolymers were systematically controlled by living anionic poly- 
merization, and the morphologies of the DGEBA blends were examined. (ii) to examine the effect of the reaction rate on the nanostructures using the each composition of the epoxy/acrylic BCP blends. From the results, the phase diagram of the epoxy/ acrylic triblock copolymer blends will be proposed.

\section{Experimental procedure}

\subsection{Materials}

The epoxy thermoset used in this study was diglycidyl ether of bisphenol-A (DGEBA), jER828 (epoxy equivalent weight: $189 \mathrm{~g} / \mathrm{eq}$., provided by Mitsubishi Chemical Co. Ltd., Japan). Phenol novolac (PN, hydroxyl group equivalent weight: $105 \mathrm{~g} / \mathrm{eq}$., provided by Sumitomo Bakelite Co., Ltd., Japan) was utilized as the curing agent. Tri phenyl phosphine (TPP, produced by Tokyo Chemical Industry Co. Ltd., Japan) was applied as a catalyst with the PN. Several types of PMMA- $b-\mathrm{PnBA}-$ $b$-PMMA triblock copolymers (acrylic BCPs) were synthesized by living anionic polymerization (produced by Kuraray Co. Ltd., Japan), and were applied as the modifiers for the epoxy blends. The molecular weight of the acrylic BCPs and the composition (the ratio of the PnBA in the acrylic BCPs) were systematically controlled. The PnBA block chain is the segment which is immiscible with the PN-cured DGEBA type epoxy thermosets [30]. The characterization of the BCPs is shown in Table 1 in detail. Also, the chemical structure of the BCPs is shown in Figure 1.

Table 1. Weight-average molecular mass $\left(M_{\mathrm{w}}\right)$, PnBA content and polydispersity of PMMA-PnBA-PMMA triblock copolymers (BCPs)

\begin{tabular}{|l|c|c|c|}
\hline No. of BCP & $\begin{array}{c}\text { Molecular mass } \\
\mathbf{M}_{\mathbf{w}}\end{array}$ & $\begin{array}{c}\text { PnBA in BCP } \\
{[\mathbf{w t} \% \mathbf{~}]}\end{array}$ & $\mathbf{M}_{\mathbf{w}} / \mathbf{M}_{\mathbf{n}}$ \\
\hline BCP50-6 & 64000 & 50 & 1.19 \\
\hline BCP68-6 & 60000 & 68 & 1.25 \\
\hline BCP77-7 & 72000 & 77 & 1.19 \\
\hline BCP70-3 & 26000 & 70 & 1.07 \\
\hline BCP69-13 & 132000 & 69 & 1.31 \\
\hline BCP79-11 & 105000 & 79 & 1.43 \\
\hline
\end{tabular}

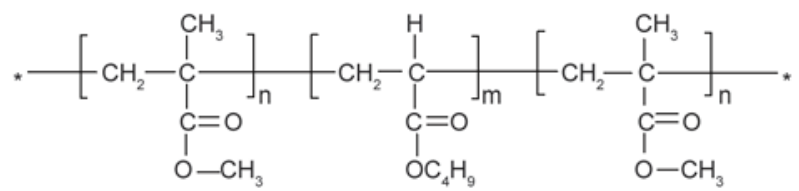

Figure 1. Chemical structure of PMMA-PnBA-PMMA triblock copolymers (BCPs)

\subsection{Size exclusion chromatography}

The molecular weight distributions of the BCPs were determined using size exclusion chromatography (SEC, PU-2080 HPLC system using JASCOBorwin-GPC program), which was equipped with two connected columns of Shodex LF-804. Tetrahydrofuran (THF) was used as the solvent. The average molecular weights were calibrated by monodispersed polystyrene standards.

\subsection{Preparation of cured thermosets}

The DGEBA/acrylic BCP systems were cured by the following procedure. First, the BCP was mixed with the DGEBA at room temperature. The mixture was heated while being stirred in an oil bath at $200^{\circ} \mathrm{C}$ for $30 \mathrm{~min}$ in order to dissolve the BCP in the DGEBA. After the mixture was cooled to below $100^{\circ} \mathrm{C}$, the stoichiometric quantities of $\mathrm{PN}$ and a small amount [0.05-2.0 parts per hundred parts of resin (DGEBA+PN): phr] of TPP were added to the mixture and degassed. The mixture was cast into a pre-treated mold with a release agent. The curing condition is shown in Table 2. The gel time was measured during the pre-curing step at $120^{\circ} \mathrm{C}$ for the thermoset compositions by using the method described in the section 2.5. After this procedure, the oven was switched off and the cured polymers were allowed to cool slowly to room temperature.

Table 2. Curing conditions and gel times of DGEBA/ acrylic-BCP blends cured with PN (catalyzed by TPP)

\begin{tabular}{|c|c|c|}
\hline $\begin{array}{c}\text { Amount of TPP } \\
\text { [phr] }\end{array}$ & $\begin{array}{c}\text { Gel time } \\
{[\mathbf{m i n}]}\end{array}$ & Curing condition \\
\cline { 1 - 2 } 2.0 & 5 & \multirow{2}{*}{$120^{\circ} \mathrm{C} 2 \mathrm{~h}+150^{\circ} \mathrm{C} 2 \mathrm{~h}$} \\
\cline { 1 - 2 } 1.0 & 8 & \\
\hline 0.5 & 15 & $120^{\circ} \mathrm{C} 4 \mathrm{~h}+150^{\circ} \mathrm{C} 2 \mathrm{~h}$ \\
\hline 0.05 & 150 &
\end{tabular}

\subsection{Microscopic observation}

\subsubsection{Transmission Electron Microscopy (TEM)}

Thin sections of the cured polymers were cryomicrotomed at $-80^{\circ} \mathrm{C}$. The setting thickness was $40-50 \mathrm{~nm}$. The microtomed thin sections of the cured polymers were stained by vapor of $\mathrm{RuO}_{4}$ and observed by a transmission electron microscope (TEM: HITACHI H-800NA, Japan) with $100 \mathrm{kV}$ as the acceleration voltage. 


\subsection{Evaluation for gel time of the epoxy/BCP blend}

The time dependencies of the viscoelastic properties (storage modulus: $G^{\prime}$ and loss modulus: $G^{\prime \prime}$ ) of the DGEBA/BCP/PN blends were evaluated by dynamic mechanical analysis (DMA) in shear mode between two parallel plates (Rheosol-G5000, UBM Co. LTD, Japan). The diameter of the parallel plates was $25 \mathrm{~mm}$, and the gap between the two plates was $2.5 \mathrm{~mm}$. The dynamic frequency was $1 \mathrm{~Hz}$ and the amplitude was $0.01^{\circ}$. The tests were conducted at $120^{\circ} \mathrm{C}$. The gel time was defined at the time when the line of $G^{\prime}$ and the line of $G^{\prime \prime}$ intersected.

\subsection{Glass transition temperature, $T_{\mathrm{g}}$, measurement for BCPs}

Glass transition temperatures of BCPs were determined using differential scanning calorimetry (DSC 6200, Seiko Instruments, Inc., Japan). Measurements were performed at a scanning rate of $40^{\circ} \mathrm{C} /$ minute. Mid-point $T_{\mathrm{g}}$ values were recorded.

\subsection{Ultra small-angle $X$-ray scattering (USAXS)}

In order to evaluate the phase separated structures of the cured epoxy/BCP blends, ultra small angle $\mathrm{X}$-ray scattering (USAXS) measurements were conducted at the BL03XU beamline at SPring-8 (Hyogo, Japan) with the approval of JASRI (Proposal No. 2010B7206). The X-ray wavelength was $0.2 \mathrm{~nm}$, and the distance between the sample and the detector (Imaging Plate) was ca. $6000 \mathrm{~mm}$. The exposure time was $10 \mathrm{sec}$.

\section{Results and discussion}

\subsection{Phase structures of cured epoxy/PMMA-PnBA-PMMA triblock copolymers}

First, the effect of the ratio of PnBA in the BCPs was examined in terms of the nanostructures of the cured epoxy (DGEBA)/BCP blends. Three types of the BCPs (BCP50-6, BCP68-6, and BCP77-7) were compared as the modifiers for the epoxy blends. The PnBA ratios in the BCPs were 50, 68, and 77\%, respectively. Figure $2(10 \mathrm{wt} \% \mathrm{BCP}$ in the blends) and Figure 3 (20 wt $\%$ BCP in the blends) show the phase structures (TEM photographs) of the DGEBA/ BCP blends. As had been clarified in our previous paper, the relatively dark phases consist of the

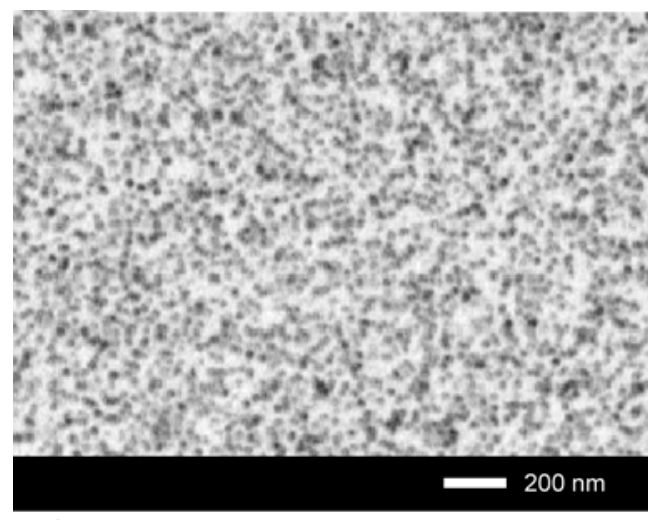

a)

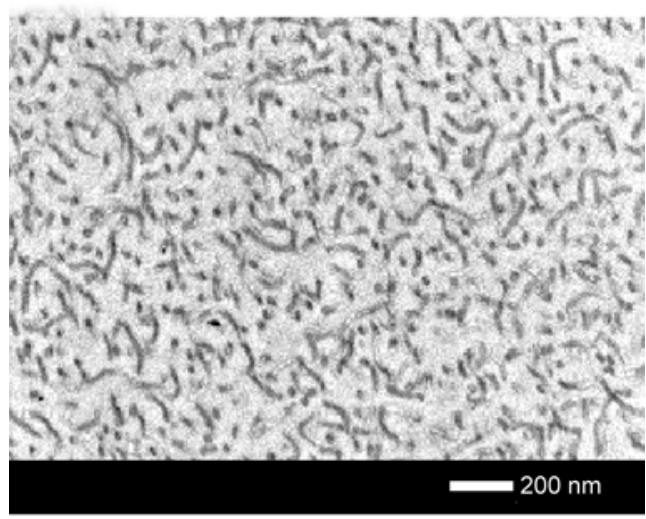

b)

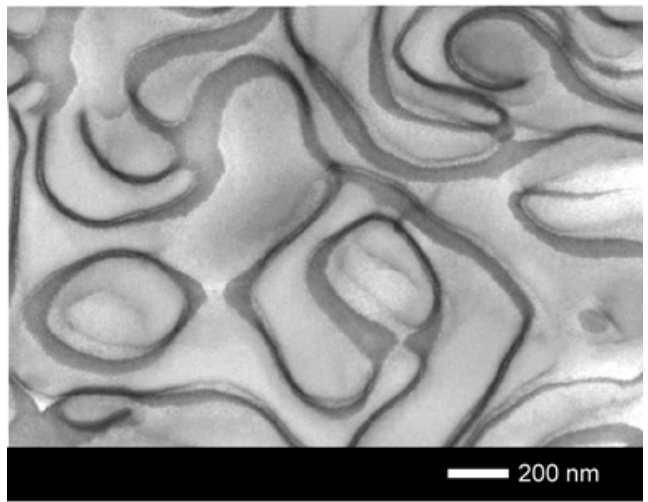

c)

Figure 2. Effect of the PnBA content in the acrylic BCPs on the phase structures of DGEBA $/ 10 \mathrm{wt} \%$ acrylic BCP blends cured with PN (catalyzed by $0.5 \mathrm{phr}$ TPP): a) DGEBA/BCP50-6 (PnBA content in the BCP: 50 wt\%), b) DGEBA/BCP68-6 (PnBA content in the BCP: $68 \mathrm{wt} \%$ ), c) DGEBA/BCP77-7 (PnBA content in the BCP: $77 \mathrm{wt} \%$ )

PnBA stained by $\mathrm{RuO}_{4}$, and the bright matrix mainly consists of the epoxy thermoset [30].

The cured blends of the DGEBA/BCP50-6 (ie. 50\% PnBA in the BCP) showed spherical nano-micelles composed of the PnBA, in both cases of the $10 \%$ BCP blend and the 20\% BCP blend. The cured blends of the DGEBA/BCP68-6 (ie. 68\% PnBA in the $\mathrm{BCP}$ ) showed cylindrical nano-micelles, in both 


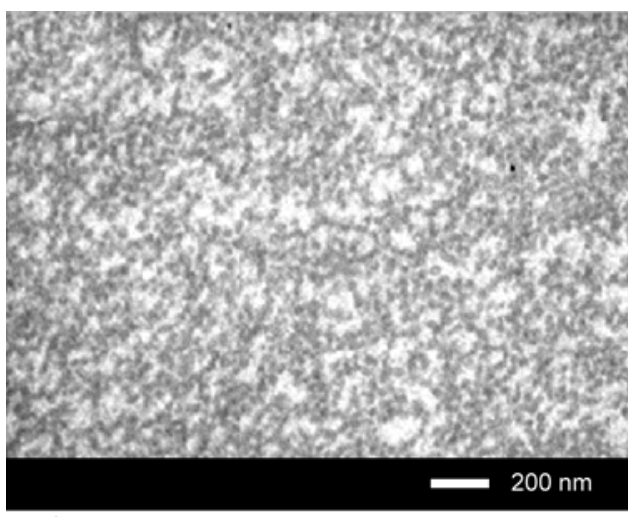

a)

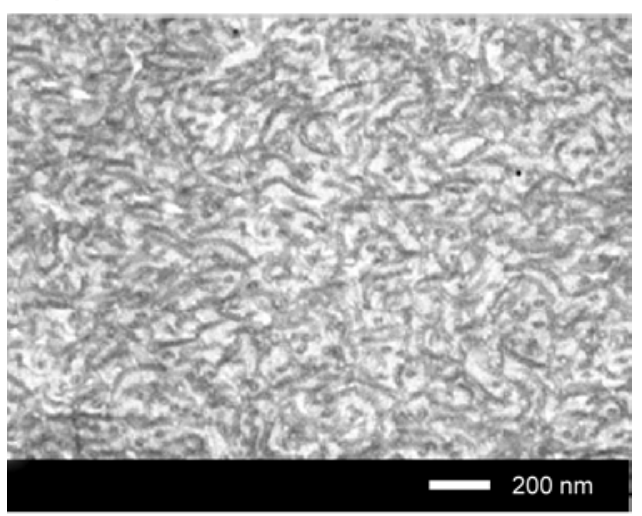

b)

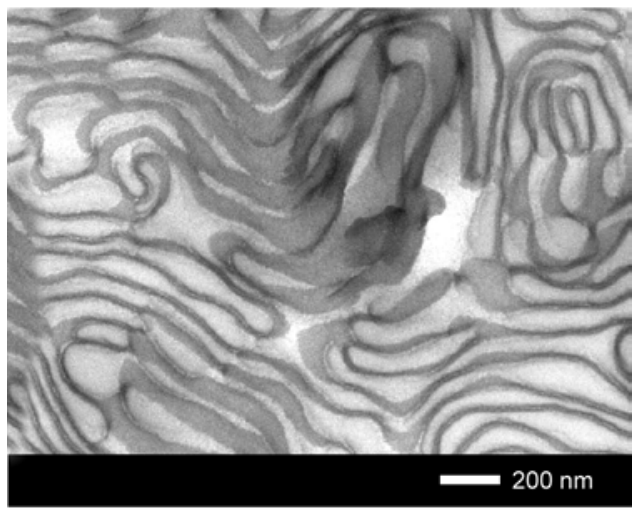

c)

Figure 3. Effect of the PnBA content in the acrylic BCPs on the phase structures of DGEBA/20 wt $\%$ acrylic BCP blends cured with PN (catalyzed by $0.5 \mathrm{phr}$ TPP): a) DGEBA/BCP50-6 (PnBA content in the BCP: $50 \mathrm{wt} \%$ ), b) DGEBA/BCP68-6 (PnBA content in the BCP: $68 \mathrm{wt} \%)$, c) DGEBA/BCP77-7 (PnBA content in the BCP: $77 \mathrm{wt} \%$ )

the cases of the $10 \% \mathrm{BCP}$ blend and the $20 \% \mathrm{BCP}$ blend. Figure 4 shows the magnified image of the $20 \%$ BCP $68-6$ blend. The diameter of the cylindrical micelles was about 20 nanometers. The branched micelles were dispersed randomly and partially connected to each other in 3-dimensional directions. And the cured blends of the DGEBA/BCP77-7 (ie. $77 \%$ PnBA in the BCP) gave nano-micelles of 'curved lamella', in the both the cases of the $10 \%$

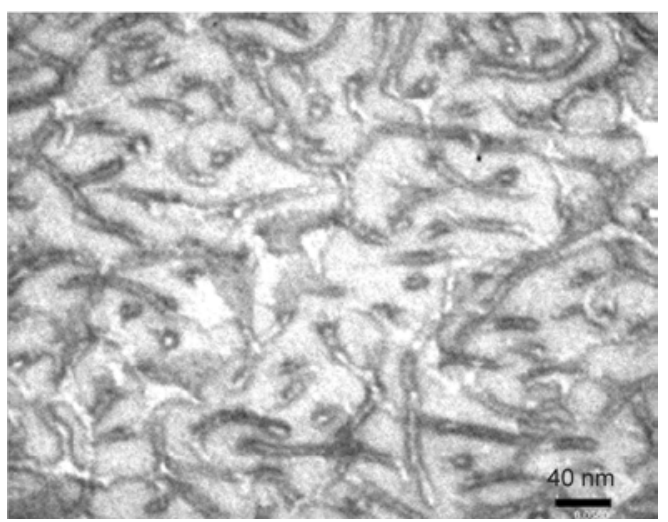

Figure 4. Phase structure (higher magnified image) of DGEBA $/ 20 \mathrm{wt} \%$ BCP68-6 blend cured with PN (PnBA content in the BCP: $68 \mathrm{wt} \%, M_{\mathrm{w}}$ of the $\mathrm{BCP}=60000)$. Note the nano-cylinders were branched in random directions.

BCP blend and the 20\% BCP blend, as shown in Figures $2 \mathrm{c}$ and $3 \mathrm{c}$. The 'curved lamella' micelles were 3-dimensionally continuous in the whole observed area.

Dean et al. [21] clarified that the methylenedianiline-cured DGEBA/PEO-PB block copolymer blends showed phase transition from spherical micelles to wormlike micelles and finally to vesicles, as the volume fraction of the epoxy-miscible block decreased [21]. The interfacial curvature could be determined by the geometrical constraints of the block copolymers, balancing the competing factors, such as achieving a constant density of the polymer chain and minimizing the chain stretching $[15,16$, 21]. Although the types of the phase structures in the present study were different from theirs, the basic rule determining the interfacial curvature was similar. Namely, the interfacial curvature of the phase structures decreased as the ratio of the epoxyimmiscible block increased (i.e. the ratio of the epoxy-miscible block decreased), from spherical micelles to branched cylindrical micelles, and to 'curved lamella' micelles.

Next, the effect of the molecular weight of the BCP was also examined in terms of the phase structures of the epoxy blends. The molecular weights of the BCPs were changed from 26000 to 132000 . In the meantime, the PnBA ratio of the BCPs was maintained at $68-70 \mathrm{wt} \%$. Therefore, the effect of the molecular weight of the BCPs could be extracted. Figure 5 (10 wt \% BCP in the blends) and Figure 6 ( $20 \mathrm{wt} \%$ BCP in the blends) show the phase structures (TEM photographs) of the epoxy/BCP blends. 


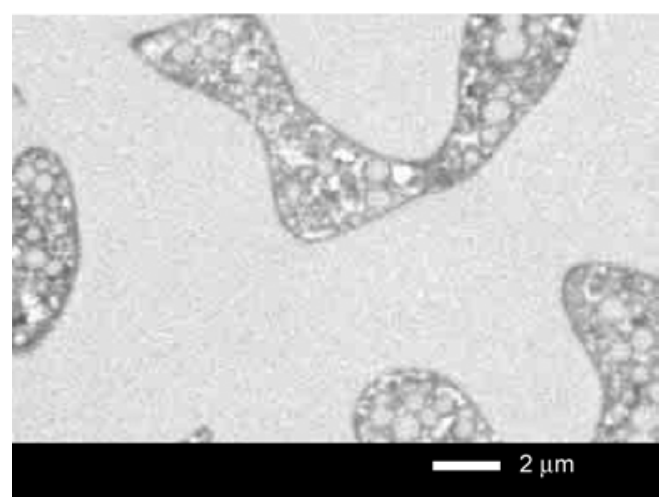

a)

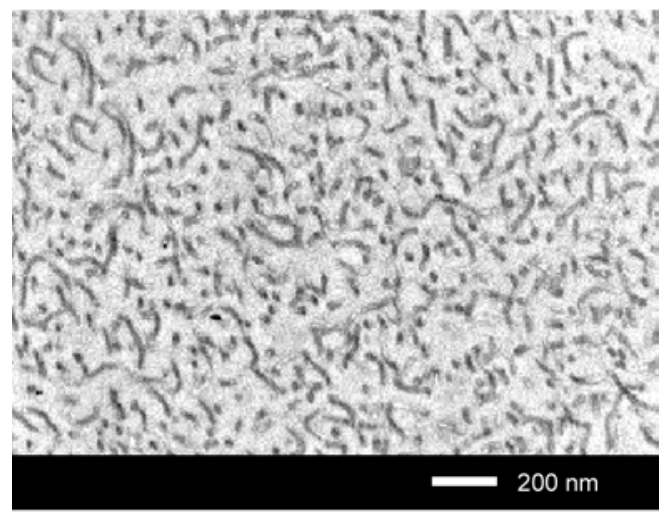

b)

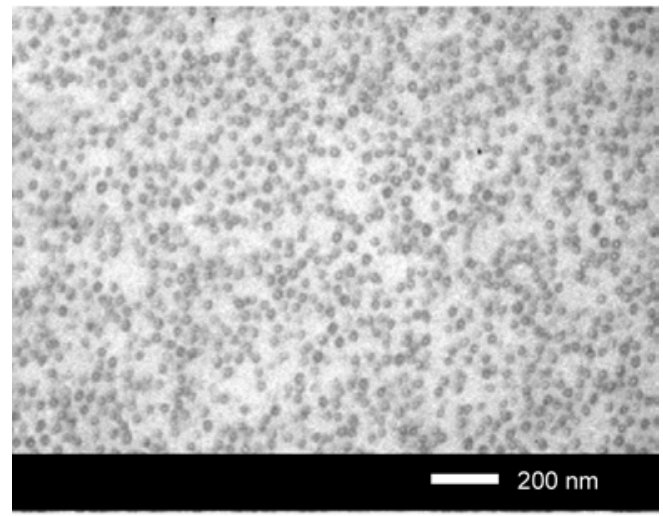

c)

Figure 5. Effect of the molecular weight of the acrylic BCPs on the phase structures of DGEBA $/ 10 \mathrm{wt} \%$ acrylic BCP blends cured with PN (catalyzed by $0.5 \mathrm{phr}$ TPP): a) DGEBA/BCP70-3 $\left(M_{\mathrm{w}}\right.$ of the BCP: $26000)$, b) DGEBA/BCP68-6 $\left(M_{\mathrm{w}}\right.$ of the BCP: $60000)$, c) DGEBA/BCP69-13 $\left(M_{\mathrm{w}}\right.$ of the BCP: $132000)$

Figure $5 \mathrm{~b}$ and Figure $6 \mathrm{~b}$ show the blends of the BCP68-6 with the molecular weight of 60000 , which were explained as in Figure $2 b$ and Figure $3 b$. Figure $5 \mathrm{c}$ and Figure $6 \mathrm{c}$ show the blends of the BCP69-13 with the molecular weight of 132000 . The blend of 10\% BCP69-13 in Figure 5c showed spherical nano-micelles. The blend of 20\% BCP6913 in Figure $6 \mathrm{c}$ showed arrayed cylindrical micelles which were dispersed regularly in an epoxy-rich

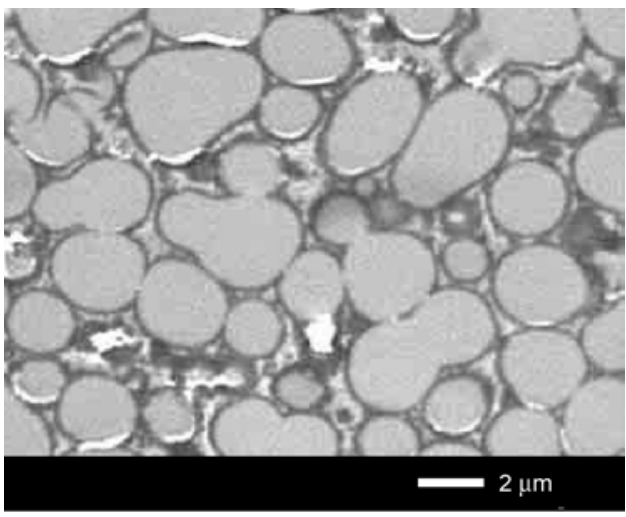

a)

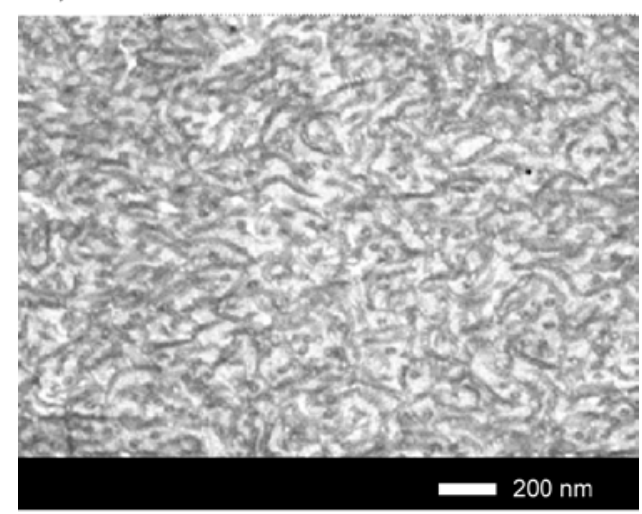

b)

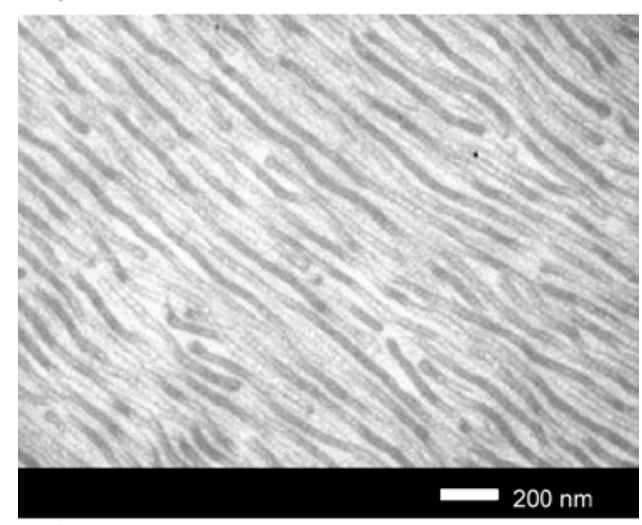

c)

Figure 6. Effect of the molecular weight of the acrylic BCPs on the phase structures of DGEBA $/ 20 \mathrm{wt} \%$ acrylic $\mathrm{BCP}$ blends cured with $\mathrm{PN}$ (catalyzed by $0.5 \mathrm{phr}$ TPP): a) DGEBA/BCP70-3 $\left(M_{\mathrm{w}}\right.$ of the BCP: $26000), \mathrm{b})$ DGEBA/BCP $68-6\left(M_{\mathrm{w}}\right.$ of the BCP: $60000)$, c) DGEBA/BCP69-13 $\left(M_{\mathrm{w}}\right.$ of the BCP: $132000)$

matrix, similar to the phase structure in our previous paper [30]. Moreover, the phase separated structure of the cured 20\% BCP69-13 blend was examined by the USAXS measurement. Figure 7 a shows the azimuthally integrated USAXS intensity against scattering vector $q$. The scattering profile is the result from both the structure factor and the form factor of the phase separated BCP blend. The first order peak, which can be assigned to the structure factor 

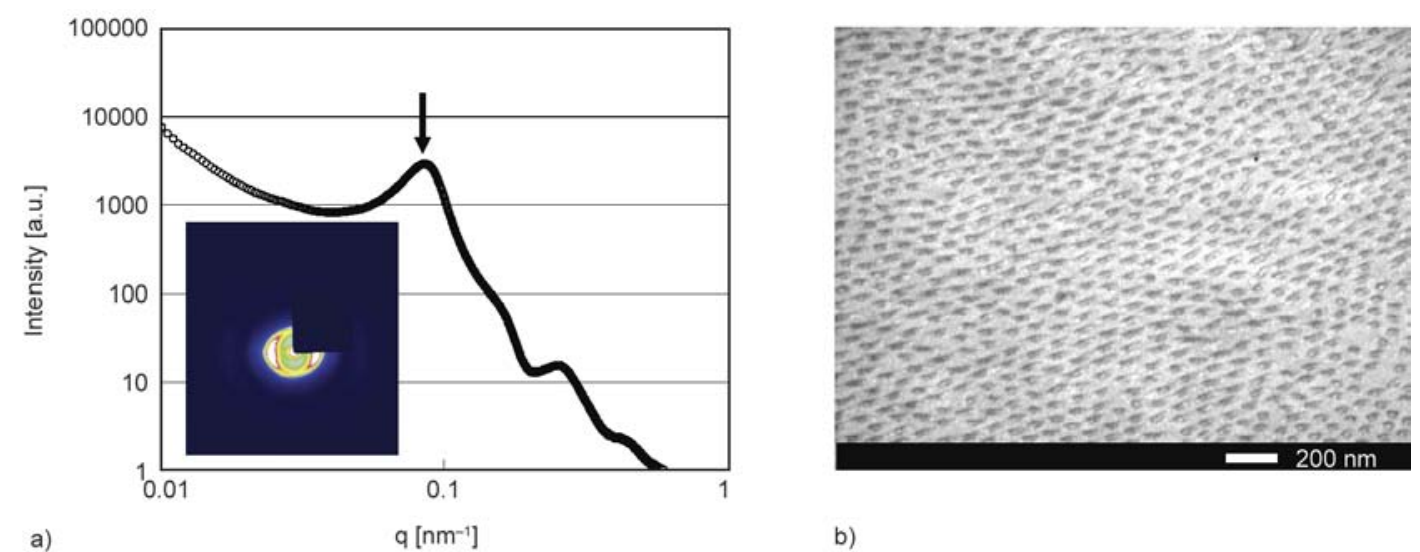

Figure 7. a) Azimuthally integrated USAXS profile for the PN-cured DGEBA/20 wt $\%$ BCP69-13 blend. The inset in the figure shows the corresponding two-dimensional images. b) Cross-section of the $20 \mathrm{wt} \% \mathrm{BCP}$ blend in Figure $6 \mathrm{c}$, which was cut from the perpendicular direction and observed by TEM. Both the USAXS profile and the TEM images suggest that the blend has the hexagonally packed cylindrical micelles.

from the phase structure, was indicated by the left arrow. The inset in the Figure 7a corresponds to the two-dimensional image of the scattering, and presents the strongly oriented phase structure. Figure $7 \mathrm{~b}$ shows the section cut from the perpendicular direction of the same blends in Figure 6c, which indicates the cross-sections of the packed cylindrical micelles. The estimated distance of the micelles from the first order peak in the Figure 7a was about $75 \mathrm{~nm}$, which is consistent with the TEM images showing the hexagonally packed cylindrical micelles. As will be discussed later, the anisotropic phase structure could be created by the growth of the initial phase structure due to the thermodynamic repulsion between the epoxy matrix and the PnBA segment which is immiscible with the epoxy matrix. The immiscibility is also the source that the form factor is pronounced. It was confirmed from the USAXS measurements that all the epoxy/BCP blends possessed the nanostructures which were indicated from the TEM observations.

Figures $5 \mathrm{a}$ and $6 \mathrm{a}$ show the cured blends of the DGEBA/BCP70-3 (the molecular weight: 26000 ). Please note the magnification of these photographs is 10 times lower than the others in Figures 5 and 6. Both the 10\% BCP70-3 blend and the 20\% BCP70-3 blend had macro-phase separation in micrometersizes. A plausible reason for the macro-phase separation of the DGEBA/BCP70-3 blends would be in the poor ability of the low molecular-weight $\mathrm{BCP}$ to stabilize the nanostructure. The phase sizes in Figures $5 \mathrm{a}$ and $6 \mathrm{a}$ were similar to those of the epoxy blends which were formed by the reaction-induced phase separation [12-14]. This suggests that the PMMA blocks in the low molecular-weight BCP were separated from the epoxy matrices in the curing process. The demixing of the PMMA block would be the trigger to make the macro-phase via reaction-induced phase separation. Moreover, the $T_{\mathrm{g}} \mathrm{s}$ of the BCPs themselves were measured by DSC to examine the properties of the blocks. In general, the PMMA- $b$-PnBA- $b$-PMMA triblock copolymer shows two $T_{\mathrm{g}} \mathrm{s}$, assigned to the PMMA block chain and the PnBA block chain. In fact, the BCP68-6 and the BCP69-13 had two $T_{\mathrm{gS}}$ at -40 and $120^{\circ} \mathrm{C}$. The first $T_{\mathrm{g}}\left(-40^{\circ} \mathrm{C}\right)$ can be assigned to the PnBA block chain, and the second $T_{\mathrm{g}}\left(120^{\circ} \mathrm{C}\right)$ can be assigned to the PMMA block chain. However, the $T_{\mathrm{g}} \mathrm{s}$ of the low molecular-weight BCP70-3 were different from these two. Namely, the $T_{\mathrm{g}}$ of the BCP70-3 were at -25 and at $40^{\circ} \mathrm{C}$, which indicated that the properties of the block chains with low molecular-weight was clearly different from those with high molecularweight. These results also suggest that the low molecular-weight PMMA block of BCP70-3 would not have same ability to stabilize the nano-phase structures in the epoxy/BCP blends, in comparison with the high molecular-weight PMMA block in other BCPs. The ability to stabilize the phase separation would be a key factor in the creation of periodical nano-phase structures in the epoxy/BCP blends, as well as the miscibility-immiscibility of the block chains to the matrix polymer [30]. 


\subsection{Influence of the reaction rate on the phase structures and the phase diagram of cured DGEBA/PMMA-PnBA-PMMA triblock copolymers}

In general, the morphology of the epoxy/thermoplastic polymer blends having a 'reaction-induced phase separation mechanism' is not determined at the thermodynamically stable state $[12,13]$. It is often affected by the curing reaction rate, because the progress of the phase separation of the blends could be frozen by the cross-link formation of the epoxies and curing agents. The final phase structures depend on the kinetics between the reactioninduced phase separation and the fixation of the phase structure by the cross-link formation. Therefore, the phase structures of each epoxy/acrylic $\mathrm{BCP}$ blend were reexamined, in terms of the effect of the reaction rate (gel time). To be specific, the gel time of the epoxy blends at $120^{\circ} \mathrm{C}$ was altered from 5 to 150 minutes by only slightly changing the amount of the catalyst (TPP), while keeping the main composition of the DGEBA/acrylic BCP/PN.

Figure 8 shows the case of the DGEBA/BCP69-13 (10 wt $\%)$ blends. The phase type was spherical

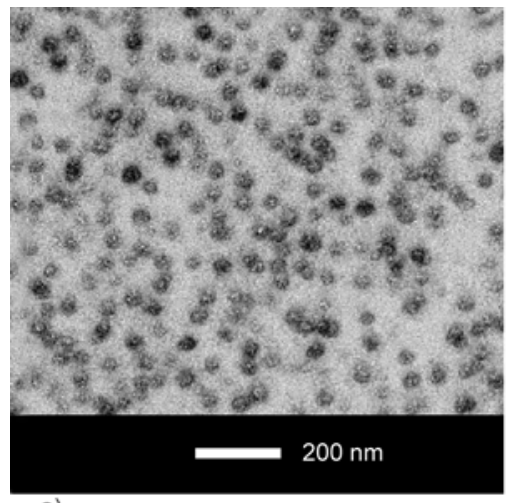

a)

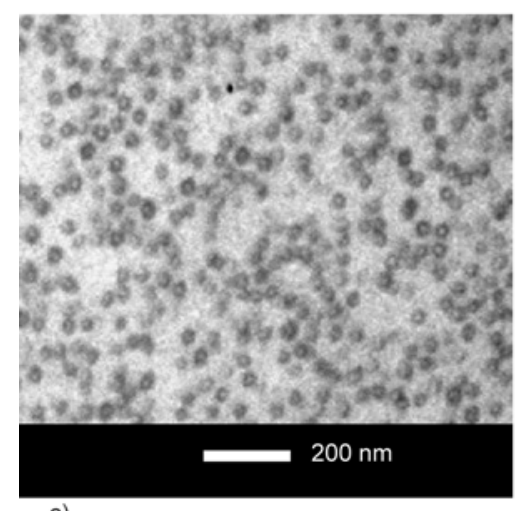

c) nano-micelles, and the phase type and the phase sizes were maintained, irrespective of the gel times. Figure 9 shows the case of random cylindrical nanomicelles of the DGEBA/BCP68-6 (10 wt \%) blends. This also indicated that the changes of the phase types and the phase sizes were not observed, irrespective of the gel times. Figure 10 shows the case of hexagonally packed cylindrical micelles of the DGEBA/BCP69-13 (20 wt \%) blends. The type of the nano-structure was roughly kept. However, the alignment of the cylinders in the blends with a gel time of 5 min was not sufficient. The alignment of the cylinders progressed according to the delay of the gel time. Figure 11 shows the case of the 'curved lamella' micelles of the DGEBA/BCP79-11 (20 wt\%) blends. Roughly speaking, the type of the nanostructure was maintained, but the alignment of the lamella progressed, with the delay of the gel time. It can be summarized that the details of the phase structures having anisotropic nature could be affected by the reaction rate though the thermodynamics was the main driving force for leading a stable state in each phase structure.

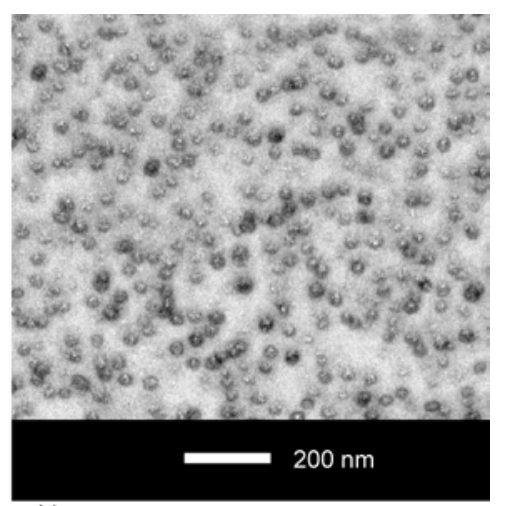

b)

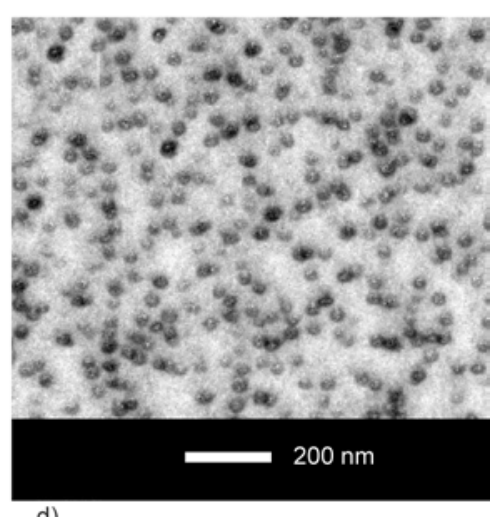

d)

Figure 8. Influences of curing reaction rate (gel time) on the phase structures of the DGEBA/BCP69-13 (PnBA content in the BCP: $69 \mathrm{wt} \%$ ) blends cured with PN. Content of the BCP in the blend: $10 \mathrm{wt} \%$. Gel time at $120^{\circ} \mathrm{C}$ : (a) $5 \mathrm{~min}$, (b) $8 \mathrm{~min}$, (c) $15 \mathrm{~min}$, (d) $150 \mathrm{~min}$. 


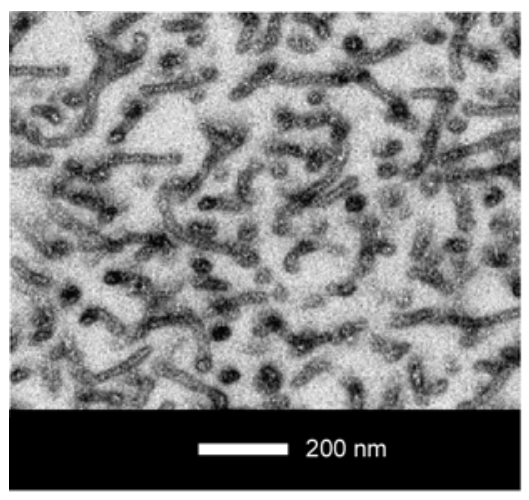

a)

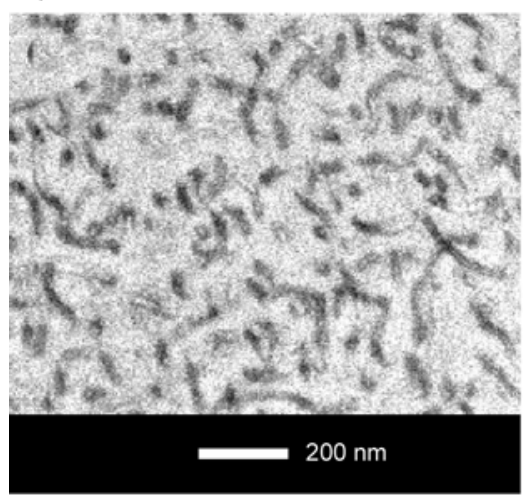

c)

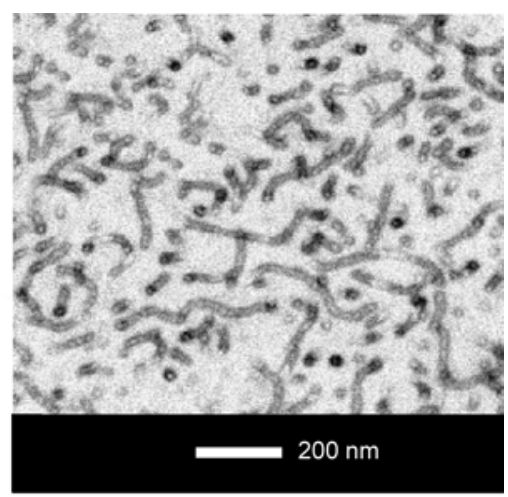

b)

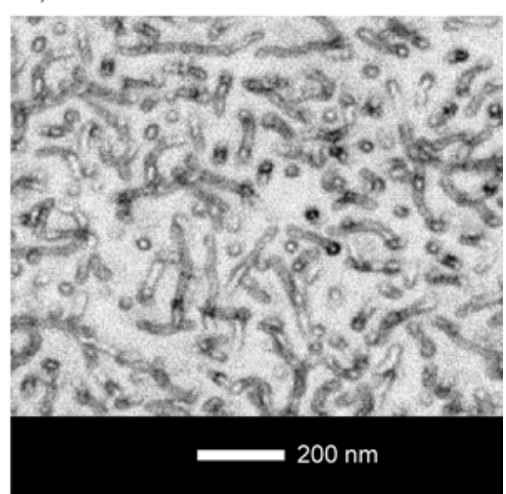

d)

Figure 9. Influences of curing reaction rate (gel time) on the phase structures of the DGEBA/BCP68-6 (PnBA content in the BCP: $68 \mathrm{wt} \%$ ) blends cured with PN. Content of the BCP in the blend: $10 \mathrm{wt} \%$. Gel time at $120^{\circ} \mathrm{C}$ : (a) $5 \mathrm{~min}$, (b) $8 \mathrm{~min}$, (c) $15 \mathrm{~min},(d) 150 \mathrm{~min}$.

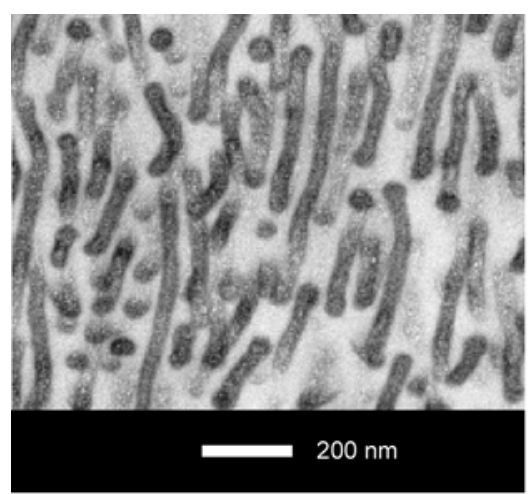

a)

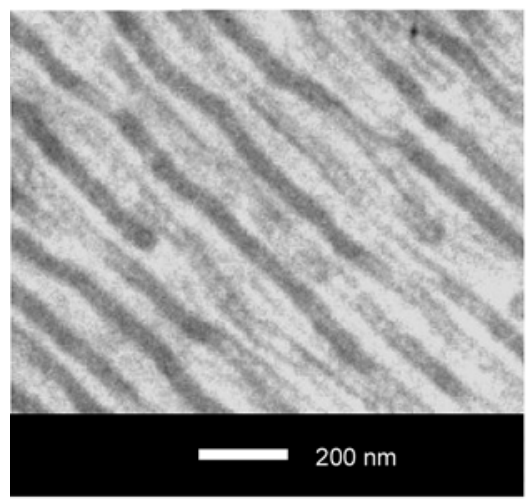

c)

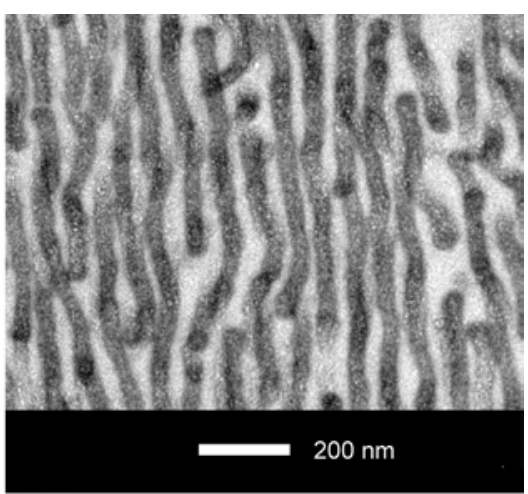

b)

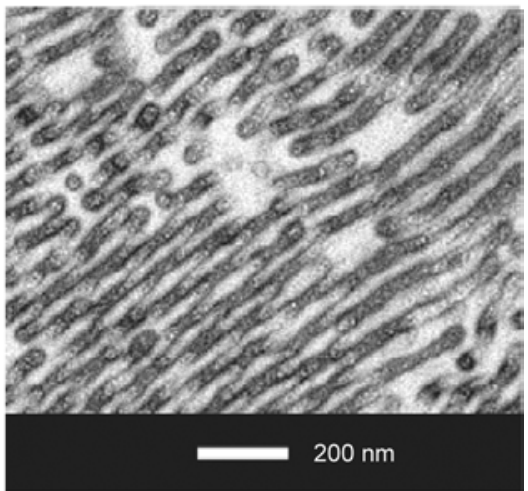

d)

Figure 10. Influences of curing reaction rate (gel time) on the phase structures of the DGEBA/BCP69-13 (PnBA content in the BCP: $69 \mathrm{wt} \%$ ) blends cured with PN. Content of the BCP in the blend: $20 \mathrm{wt} \%$. Gel time at $120^{\circ} \mathrm{C}$ : (a) $5 \mathrm{~min}$, (b) $8 \mathrm{~min}$, (c) $15 \mathrm{~min}$, (d) $150 \mathrm{~min}$. 


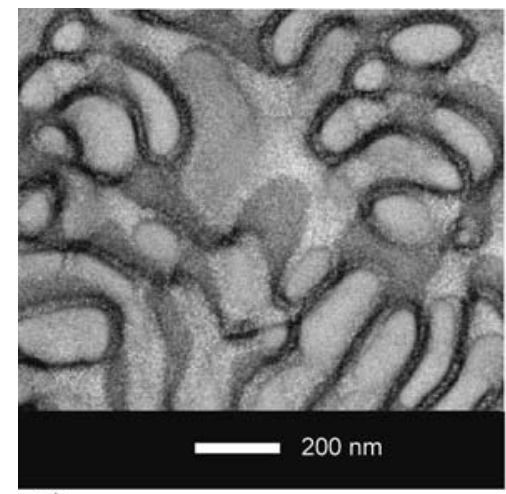

a)

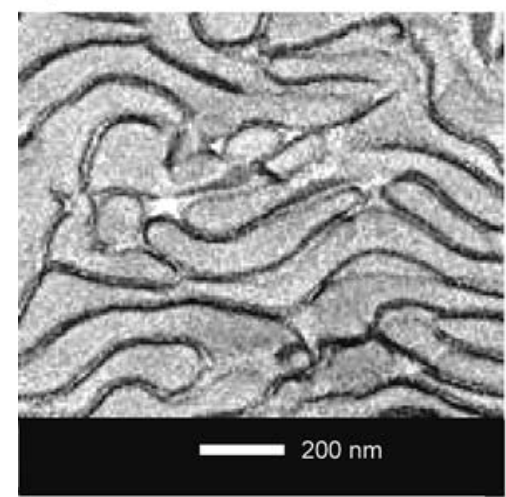

c)

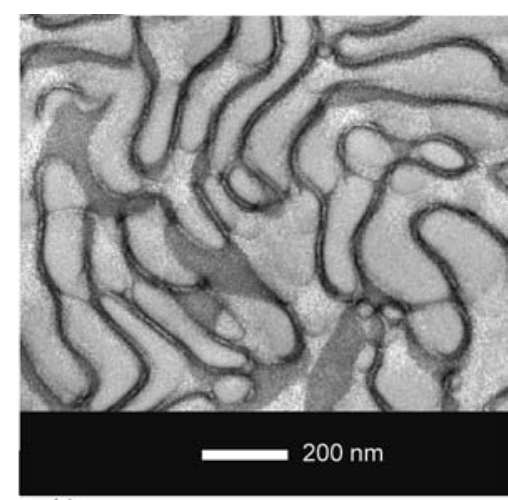

b)

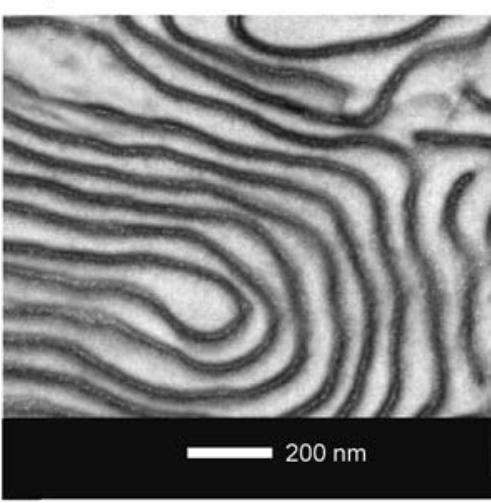

d)

Figure 11. Influences of curing reaction rate (gel time) on the phase structures of the DGEBA/BCP79-11 (PnBA content in the BCP: $79 \mathrm{wt} \%$ ) blends cured with PN. Content of the BCP in the blend: $20 \mathrm{wt} \%$. Gel time at $120^{\circ} \mathrm{C}$ : (a) $5 \mathrm{~min}$, (b) $8 \mathrm{~min}$, (c) $15 \mathrm{~min}$, (d) $150 \mathrm{~min}$.

On the other hand, the types of the nanostructures were maintained in this study, irrespective of the gel time, under the condition of keeping the main composition of the blends. Specifically, the phase structures in the PN-cured DGEBA/acrylic BCP blends were roughly determined from the compositions of the blends. This is probably because the seeds of the nanostructures already existed in the blends before the start of the reaction of epoxy and PN $[15,16]$. Figure 12 is the initial SAXS profile for the DGEBA/ $20 \mathrm{wt} \%$ BCP69-13 blend which is just reaching $120^{\circ} \mathrm{C}$. This is the evidence to show the existence of the seeds of the cylindrical nanostructure before the curing. Of course, the USAXS results do not mean that there was no change in the phase structures in the curing process. In-situ SAXS analyses during the curing process are necessary to verify the details of the structure change of the DGEBA/acrylic BCP blends, which will be clarified in the next paper. However, the USAXS results (Figure 12) indicated clearly that the nanostructure existed before the curing. The seeds of the nanostructures were formed via 'self-assembly' mechanism, not formed via 'reaction-induced phase separation' mechanism. Meanwhile, Romeo et al. [37] reported that the cure cycle

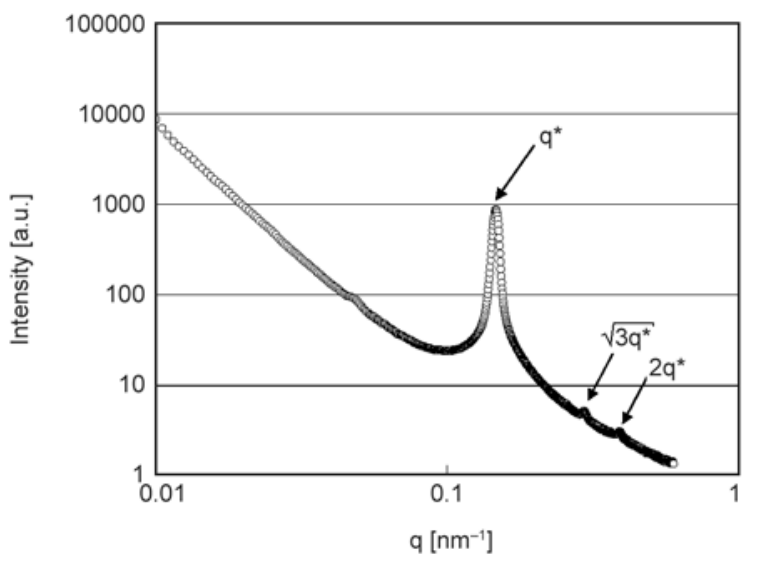

Figure 12. USAXS profile for the DGEBA/20 wt $\%$ BCP6913 blend just reaching $120^{\circ} \mathrm{C}$ (before the curing). The profile suggests the hexagonally packed cylindrical micelles.

affected the types of the nanostructures of a DGEBA/ PS- $b$-PMMA BCP blend which were formed via 'reaction-induced phase separation'. The selected blend in the literature firstly made a homogeneous solution before the curing, and phase-separated in the curing process. The 'reaction-induced phase separation' would be favorable in terms of giving the versatile morphologies of the epoxy/BCP blends by changing the cure cycle. On the other hand, the 


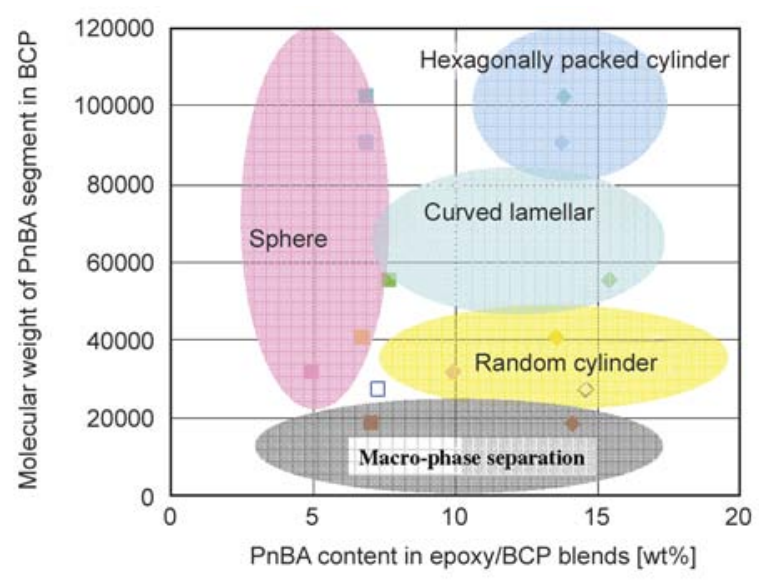

Figure 13. Phase diagram of the DGEBA/acrylic-BCP blends cured with PN (catalyzed by TPP)

experimental results obtained in our study may suggest the advantage of the 'self-assembly' system in terms of giving robustness of the nanostructures of the epoxy/BCP blends, against the change of the curing conditions.

As the final stage of the present paper, we tried to describe a phase diagram of the PN-cured DGEBA/ PMMA- $b$-PnBA- $b$-PMMA triblock copolymer blends, as shown in Figure 13. The horizontal axis shows the amount of the PnBA block chain in whole blend polymers, and the vertical axis shows the molecular weight of the PnBA block chain of the BCPs. The phase diagram described the regions of nano-spheres, hexagonally packed cylinders, curved lamellae, randomly dispersed cylinders, and the macro phase separation. The PnBA block chains of the BCPs were immiscible with the PN-cured DGEBA [30]. Namely, it can be summarized that the nanostructures of the PN-cured DGEBA/PMMA- $b$ PnBA- $b$-PMMA triblock copolymer blends were controlled by the molecular weight of the immiscible PnBA-block chain and the ratio of the PnBA in the blends. The information could become the basis to control the morphology and the mechanical properties of the DGEBA/acrylic BCP blends.

\section{Conclusions}

Nanostructures of DGEBA/PMMA- $b$-PnBA- $b$ PMMA triblock copolymers (acrylic BCPs) were studied. Several nanostructures, such as spheres, cylinders (hexagonally-packed or randomly-dispersed), curved lamellae, were observed in the cured epoxy blends using a transmission electron microscope. It was found that the nanostructures were controlled by the molecular weight of the immisci- ble PnBA-block chain and the ratio of the PnBA in the blends. Moreover, the effect of the gel time to the nanostructures in the blends was examined by altering the trace amount of the catalyst. When the compositions of the epoxy blends were maintained, the types of the nanostructures were almost always maintained, irrespective of the difference of the gel time. The USAXS results indicated clearly that the nanostructures existed before the curing. The seeds of the nanostructures were formed via 'self-assembly' mechanism, not formed via 'reaction-induced phase separation'. From these experimental results, a phase diagram of the cured DGEBA/acrylic BCP blends was proposed.

\section{Acknowledgements}

This work was financially supported by a Grant-in Aid for Scientific Research (24360280) from the Ministry of Education, Culture, Sports, Science and Technology, and also by Yazaki Corporation.

\section{References}

[1] Kinloch A. J., Shaw S. J., Tod D. A., Hunston D. A.: Deformation and fracture behaviour of a rubber-toughened epoxy: 1. Microstructure and fracture studies. Polymer, 24, 1341-1354 (1983).

DOI: 10.1016/0032-3861(83)90070-8

[2] Yee A. F., Pearson R. E.: Toughening mechanisms in elastomer-modified epoxies, Part 1. Mechanical studies. Journal of Materials Science, 21, 2462-2474 (1986). DOI: $10.1007 / \mathrm{BF} 01114293$

[3] Pearson R. E., Yee A. F.: Toughening mechanisms in elastomer-modified epoxies, Part 2. Microscopy studies. Journal of Materials Science, 21, 2475-2488 (1986). DOI: $10.1007 / \mathrm{BF} 01114294$

[4] Pearson R. E., Yee A. F.: Toughening mechanisms in elastomer-modified epoxies, Part 3. The effect of crosslink density. Journal of Materials Science, 24, 25712580 (1989).

DOI: $10.1007 / \mathrm{BF} 01174528$

[5] Yee A. F., Li D., Li X.: The importance of constraint relief caused by rubber cavitation in the toughening of epoxy. Journal of Materials Science, 28, 6392-6398 (1993).

DOI: $10.1007 / \mathrm{BF} 01352202$

[6] Kishi H., Shi Y-B., Huang J., Yee A. F.: Ductility and toughenability study of epoxy resins under multiaxial stress states. Journal of Materials Science, 33, 34793488 (1998).

DOI: 10.1023/A:1013222421843

[7] Bucknall C. B., Partridge I. K.: Phase separation in epoxy resins containing polyethersulphone. Polymer, 24, 639-644 (1983). DOI: $10.1016 / 0032-3861(83) 90120-9$ 
[8] Raghava R. S.: Development and characterization of thermosetting-thermoplastic polymer blends for applications in damage-tolerant composites. Journal of Polymer Science Part B: Polymer Physics, 26, 65-81 (1988). DOI: $10.1002 /$ polb.1988.090260103

[9] Bucknall C. B., Gilbert A. H.: Toughening tetrafunctional epoxy resins using polyetherimide. Polymer, 30, 213-217 (1989).

DOI: 10.1016/0032-3861(89)90107-9

[10] Hedrick J. L., Yilgor I., Jurek M., Hedrick J. C., Wilkes G. L., McGrath J. E.: Chemical modification of matrix resin networks with engineering thermoplastics: 1. Synthesis, morphology, physical behaviour and toughening mechanisms of poly(arylene ether sulphone) modified epoxy networks. Polymer, 32, 2020-2032 (1991). DOI: 10.1016/0032-3861(91)90168-I

[11] Kishi H., Odagiri N.: Toughened thermoset resin matrix composites. in 'Series in materials science and engineering - Aerospace materials' (eds.: Cantor B., Assender H., Grant P.) Institute of Physics Publishing, Bristol, Chapter 14, 187-198 (2001).

[12] Yamanaka K., Inoue T.: Structure development in epoxy resin modified with poly(ether sulphone). Polymer, 30, 662-667 (1989).

DOI: $10.1016 / 0032-3861(89) 90151-1$

[13] Yamanaka K., Takagi Y., Inoue T.: Reaction-induced phase separation in rubber-modified epoxy resins. Polymer, 30, 1839-1844 (1989).

DOI: 10.1016/0032-3861(89)90355-8

[14] Williams R. J. J., Rozenberg B. A., Pascault J-P.: Reaction-induced phase separation in modified thermosetting polymers. Advances in Polymer Science, Polymer Analysis Polymer Physics, 128, 95-156 (1997).

DOI: $10.1007 / 3-540-61218-17$

[15] Hillmyer M. A., Lipic P. M., Hajduk D. A., Almdal K., Bates F. S.: Self-assembly and polymerization of epoxy resin-amphiphilic block copolymer nanocomposites. Journal of the American Chemical Society, 119, 27492750 (1997).

DOI: $10.1021 / \mathrm{ja} 963622 \mathrm{~m}$

[16] Lipic P. M., Bates F. S., Hillymer M. A.: Nanostructured thermosets from self-assembled amphiphilic block copolymer/epoxy resin mixtures. Journal of the American Chemical Society, 120, 8963-8970 (1998).

DOI: $10.1021 /$ ja981544s

[17] Mijovic J., Shen M., Sy J. W., Mondragon I.: Dynamics and morphology in nanostructured thermoset network/block copolymer blends during network formation. Macromolecules, 33, 5235-5244 (2000).

DOI: $10.1021 / \mathrm{ma} 991894 \mathrm{e}$

[18] Dean J. M., Lipic P. M., Grubbs R. B., Cook R. F., Bates F. S.: Micellar structure and mechanical properties of block copolymer-modified epoxies. Journal of Polymer Science Part B: Polymer Physics, 39, 29963010 (2001).

DOI: $10.1002 /$ polb.10062
[19] Guo Q., Thomann R., Gronski W., Thurn-Albrecht T.: Phase behavior, crystallization, and hierarchical nanostructures in self-organized thermoset blends of epoxy resin and amphiphilic poly(ethylene oxide)-block-poly (propylene oxide)-block-poly(ethylene oxide) triblock copolymers. Macromolecules, 35, 3133-3144 (2002). DOI: $\underline{10.1021 / \mathrm{ma} 011971 \mathrm{~h}}$

[20] Dean J. M., Verghese N. E., Pham H. Q., Bates F. S.: Nanostructure toughened epoxy resins. Macromolecules, 36, 9267-9270 (2003). DOI: $10.1021 / \mathrm{ma} 034807 \mathrm{y}$

[21] Dean J. M., Grubbs R. B., Saad W., Cook R. F., Bates F. S.: Mechanical properties of block copolymer vesicle and micelle modified epoxies. Journal of Polymer Science Part B: Polymer Physics, 41, 2444-2456 (2003). DOI: $10.1002 /$ polb.10595

[22] Wu J., Thio Y. S., Bates F. S.: Structure and properties of PBO-PEO diblock copolymer modified epoxy. Journal of Polymer Science Part B: Polymer Physics, 43, 1950-1965 (2005).

DOI: $10.1002 /$ polb.20488

[23] Ritzenthaler S., Court F., David L., Girard-Reydet E., Leibler L., Pascault J. P.: ABC triblock copolymers/ epoxy-diamine blends. 1. Keys to achieve nanostructured thermosets. Macromolecules, 35, 6245-6254 (2002).

DOI: $10.1021 / \mathrm{ma} 0121868$

[24] Ritzenthaler S., Court F., Girard-Reydet E., Leibler L., Pascault J. P.: ABC triblock copolymers/epoxy-diamine blends. 2. Parameters controlling the morphologies and properties. Macromolecules, 36, 118-126 (2003). DOI: $10.1021 / \mathrm{ma} 0211075$

[25] Maiez-Tribut S., Pascault J. P., Soulé E. R., Borrajo J., Williams R. J. J.: Nanostructured epoxies based on the self-assembly of block copolymers: A new miscible block that can be tailored to different epoxy formulations. Macromolecules, 40, 1268-1273 (2007). DOI: $10.1021 / \mathrm{ma} 0621851$

[26] Gerard P., Boupat N. P., Fine T., Gervat L., Pascault JP.: Toughness properties of lightly crosslinked epoxies using block copolymers. Macromolecular Symposia, 256, 55-64 (2007).

DOI: $\underline{10.1002 / \mathrm{masy} .200751006}$

[27] Rebizant V., Abetz V., Tournilhac F., Court F., Leibler L.: Reactive tetrablock copolymers containing glycidyl methacrylate. synthesis and morphology control in epoxy-amine networks. Macromolecules, 36, 98899896 (2003). DOI: $10.1021 / \mathrm{ma} 0347565$

[28] Rebizant V., Venet A-S., Tournilhac F., Girard-Reydet E., Navarro C., Pascault J-P., Leibler L.: Chemistry and mechanical properties of epoxy-based thermosets reinforced by reactive and nonreactive SBMX block copolymers. Macromolecules, 37, 8017-8027 (2004). DOI: $10.1021 / \mathrm{ma} 0490754$ 
[29] Serrano E., Tercjak A., Ocando C., Larrañaga M., Parellada M. D., Corona-Galván S., Mecerreyes D., Zafeiropoulos N. E., Stamm M., Mondragon I.: Curing behavior and final properties of nanostructured thermosetting systems modified with epoxidized styrene-butadiene linear diblock copolymers. Macromolecular Chemistry and Physics, 208, 2281-2292 (2007).

DOI: $10.1002 / \mathrm{macp} .200700169$

[30] Kishi H., Kunimitsu Y., Imade J., Oshita S., Morishita Y., Asada M.: Nano-phase structures and mechanical properties of epoxy/acryl triblock copolymer alloys. Polymer, 52, 760-768 (2011).

DOI: $10.1016 /$ j.polymer.2010.12.025

[31] Meng F., Zheng S., Zhang W., Li H., Liang Q.: Nanostructured thermosetting blends of epoxy resin and amphiphilic poly( $\varepsilon$-caprolactone)-block-polybutadiene-block-poly( $\varepsilon$-caprolactone) triblock copolymer. Macromolecules, 39, 711-719 (2006).

DOI: $10.1021 / \mathrm{ma} 0518499$

[32] Meng F., Zheng S., Li H., Liang Q., Liu T.: Formation of ordered nanostructures in epoxy thermosets: A mechanism of reaction-induced microphase separation. Macromolecules, 39, 5072-5080 (2006).

DOI: $10.1021 / \mathrm{ma} 060004+$

[33] Yu R., Zheng S.: Morphological transition from spherical to lamellar nanophases in epoxy thermosets containing poly(ethylene oxide)-block-poly( $\varepsilon$-caprolactone)-block-polystyrene triblock copolymer by hardeners. Macromolecules, 44, 8546-8557 (2011). DOI: $10.1021 / \mathrm{ma} 201456 \mathrm{x}$

[34] Yu R., Zheng S., Li X., Wang J.: Reaction-induced microphase separation in epoxy thermosets containing block copolymers composed of polystyrene and poly ( $\varepsilon$-caprolactone): Influence of copolymer architectures on formation of nanophases. Macromolecules, 45, 9155-9168 (2012).

DOI: $10.1021 / \mathrm{ma} 3017212$
[35] Liu J., Sue H-J., Thompson Z. J., Bates F. S., Dettloff M., Jacob G., Verghese N., Pham H.: Nanocavitation in self-assembled amphiphilic block copolymer-modified epoxy. Macromolecules, 41, 7616-7624 (2008). DOI: $10.1021 / \mathrm{ma} 801037 \mathrm{q}$

[36] Thompson Z. J., Hillymer M. A., Liu J., Sue H-J., Dettloff M., Bates F. S.: Block copolymer toughened epoxy: Role of cross-link density. Macromolecules, 42, 2333-2335 (2009).

DOI: $10.1021 / \mathrm{ma900061b}$

[37] Romeo H. E., Zucchi I. A., Rico M., Hoppe C. E., Williams R. J. J.: From spherical micelles to hexagonally packed cylinders: The cure cycle determines nanostructures generated in block copolymer/epoxy blends. Macromolecules, 46, 4854-4861 (2013). DOI: $10.1021 / \mathrm{ma} 400778 \mathrm{~s}$

[38] Inoue T., Soen T., Hashimoto T., Kawai H.: Thermodynamic interpretation of domain structure in solventcast films of A-B type block copolymers of styrene and isoprene. Journal of Polymer Science Part A-2: Polymer Physics, 7, 1283-1301 (1969). DOI: $10.1002 /$ pol.1969.160070801

[39] Matsuo M., Sagae S., Asai H.: Fine structures of styrenebutadiene block copolymer films cast from toluene solution. Polymer, 10, 79-87 (1969). DOI: 10.1016/0032-3861(69)90010-X

[40] Matsen M. W., Bates F. S.: Unifying weak- and strongsegregation block copolymer theories. Macromolecules, 29, 1091-1098 (1996). DOI: $10.1021 / \mathrm{ma} 951138 \mathrm{i}$ 